\title{
Studies on "Big" Growth Hormone from Human Plasma and Pituitary
}

\author{
Donald R. Wrught, A. David Goodman, and Kathleen D. Trimble \\ From the Division of Endocrinology and Metabolism, Department of Medicine, \\ Albany Medical College, Albany, New York 12208
}

\begin{abstract}
A BSTRACT Most of the immunoreactive growth hormone (IRGH) in human plasma elutes from Sephadex G-75 as "little" GH (LGH), mol wt 22,000, but $14-39 \%$ elutes earlier ("big" $\mathrm{GH}, \mathrm{BGH}$ ). In saline extracts of human pituitary, $11-17 \%$ of IRGH eluted as BGH. On gel filtration of pituitary and plasma $\mathrm{BGH}$ in $8 \mathrm{M}$ urea, $59-81 \%$ ran as LGH, but when the remaining $\mathrm{BGH}$ was refiltered in urea, all ran as BGH. Thus there is a "urea-stable" and a "urealabile" form of BGH. Similarly, freezing and thawing converted over half of pituitary and plasma $\mathrm{BGH}$ to LGH, but when the "freeze-stable" BGH was again frozen, thawed, and refiltered, almost all ran as BGH. Urea-stable BGH was not dissociated by freezing, and most of the freeze-stable $\mathrm{BGH}$ was stable in urea, so the two forms are very similar or identical. Since $8 \mathrm{M}$ urea and freezing dissociate peptides linked by noncovalent bonds, probably the $\mathrm{BGH}$ that is dissociated by urea and freezing consists of LGH bound noncovalently to another moiety, while in stable $\mathrm{BGH}$ the $\mathrm{LGH}$ is bound to another molecule by covalent or unusually strong noncovalent linkage. On centrifugation, the sedimentation of urea-stable $\mathrm{BGH}$ was consistent with a mol wt about twice that of LGH. Trypsinization of urea-stable BGH converted $36-59 \%$ to $\mathrm{LGH}$, suggesting that some $\mathrm{BGH}$ may be a "prohormone" of LGH. On retrypsinization of the BGH that was not converted to LGH, only $13-24 \%$ converted, suggesting that there may be two forms of urea-stable BGH which vary in their response to trypsin.
\end{abstract}

A portion of this work was presented at the national meeting of the Endocrine Society, Chicago, Ill., 21 June 1973.

Dr. Wright was the recipient of a National Institutes of Health Clinical Traineeship (T01-AM05652).

Received for publication 13 March 1974 and in revised form 12 June 1974.

\section{INTRODUCTION}

In a previous study, we investigated the possibility that immunoreactive growth hormone (IRGH) ${ }^{1}$ in human plasma is composed of more than one molecular species (1). The work was prompted in part by earlier studies on this subject by Bala, Ferguson, and Beck (2), and by Berson and Yalow (3). Plasma from acromegalic and normal subjects was fractionated on Sephadex G-75, and IRGH was measured in the effluent fractions. In every sample studied, almost all of the IRGH was found in two discrete peaks. In every instance the more retarded component ("little" IRGH, LGH) migrated almost identically with the major component of radioiodinated human pituitary $\mathrm{GH}$ (mol wt 22,000), while "big" IRGH (BGH) migrated at a rate consistent with a molecular size about twice that of LGH. BGH constituted 14-28\% of total IRGH in the plasma of the acromegalics and $25-28 \%$ in the normal subjects. Two peaks of IRGH, indistinguishable from plasma $\mathrm{BGH}$ and $\mathrm{LGH}$, were observed on gel filtration of "clinical grade" human pituitary GH. Similar results have been reported by Gorden, Lesniak, Hendricks, and Roth $(4,5)$.

In our study, on rechromatography of LGH and of BGH freshly isolated from plasma, there was no conversion of one form to the other (1). However, some conversion of $\mathrm{BGH}$ to $\mathrm{LGH}$ was noted in preparations of $\mathrm{BGH}$ stored at $-20^{\circ} \mathrm{C}$.

In the present investigation, we have extracted $\mathrm{BGH}$ from saline extracts of human pituitary as well as from normal and acromegalic plasma, and have attempted to define some of its characteristics. The results of the study indicate that there are at least two distinct

1 Abbreviations used in this paper: B/F, bound/free; BGH, big IRGH; GH, growth hormone; HGH, human GH; IRGH, immunoreactive GH; LGH, little IRGH; pituitary. 
forms of $\mathrm{BGH}$ in plasma and in pituitary extracts, and suggest the possibility that one of these forms may be a precursor or "prohormone" of LGH.

\section{METHODS}

Gel filtration. Gel filtration was carried out as previously described (1), with the following modifications. Human gamma globulin (Miles Laboratories, Inc., Miles Research Div., Kankakee, I11.) was iodinated with ${ }^{125} \mathrm{I}$ by a modification of the method of Hunter and Greenwood (6), and added to the plasma and pituitary samples before gel filtration to serve as a column marker. The other column markers employed were [ $\left.{ }^{131} \mathrm{I}\right]$ albumin and $\left.{ }^{131} \mathrm{I}\right]$ sodium iodide obtained from E. R. Squibb \& Sons, Princeton, N. J., and ${ }^{125}$ I-labeled LGH. The latter was prepared from ${ }^{125} \mathrm{I}$-labeled pituitary GH (pHGH) obtained from Cambridge Nuclear Corp., Cambridge, Mass., by filtering the material through a $2.5 \times 80-\mathrm{cm}$ Sephadex G-75 column as previously described (1), counting the ${ }^{125} \mathrm{I}$ in the effluent tubes, and pooling the fractions of the major peak, which eluted at a point consistent with a mol wt of approximately 22,000.

In the studies in which gel filtration was carried out in urea, urea (Fisher Scientific Co., Pittsburgh, Pa.) was dissolved in the filtration sample to a concentration of $8 \mathrm{M}$, and the sample was placed on a column containing Sephadex G-75 equilibrated with $8 \mathrm{M}$ urea in $0.04 \mathrm{M}$ barbital buffer, $\mathrm{pH} 8.2$, containing $0.3 \%$ albumin. The sample was run through the column at $25^{\circ} \mathrm{C}$ at a rate of $10-20 \mathrm{ml} / \mathrm{h}$, with the same solution.

In the preparation of $\mathrm{BGH}$ from the plasma of subject A. F. for gel filtration in urea, $10 \mathrm{ml}$ of plasma was gelfiltered in barbital buffer on three separate occasions, the effluent fractions containing the $\mathrm{BGH}$ were pooled, and the pool was concentrated from an initial volume of $60 \mathrm{ml}$ to $10 \mathrm{ml}$ by pressure dialysis through an Amicon UM-2 filtration membrane (Amicon Corp., Lexington, Mass.). In experiments in which effluent fractions containing urea were subsequently gel-filtered in the absence of urea, the urea was removed from the pooled fractions by dialysis against the albumin-containing barbital buffer with a cellulose dialysis membrane with a pore diameter of $4.8 \mathrm{~nm}$ (Fischer Scientific Co.). The immunochemical grade $\mathrm{pHGH}$ used in this study was obtained from the National Institute of Arthritis, Metabolism and Digestive Diseases, Bethesda, Md.

GH radioimmunoassay. The radioimmunoassay procedure was used as outlined previously (1), with the following modifications. The anti-HGH antibody employed was a guinea pig antibody prepared by Drs. S. Berson and R. Yalow and provided by the National Institute of Arthritis, Metabolism and Digestive Diseases, Bethesda, Md. Where rapid results were desired, the $\left[{ }^{125} \mathrm{I}\right] \mathrm{HGH}$ was added immediately to the reactions tubes, which were incubated for 16-24 $\mathrm{h}$ before charcoal separation and counting. Performed in this manner, the assay was sensitive to 0.125 ng/assay tube. Where greater sensitivity was required, the assay tubes were incubated without ${ }^{125} \mathrm{I}$ for 3-4 days, at which time the iodinated hormone was added, and the tubes were incubated an additional 1-2 days before separation. Under these conditions, the assay was usually sensitive to $0.015 \mathrm{ng} /$ assay tube. As we have observed that urea affects the results of our radioimmunoassay for $\mathrm{HGH}$, in assays of effluent samples containing $8 \mathrm{M}$ urea, we added $0.2 \mathrm{ml}$ of the effluent diluted appropriately in the urea-con- taining buffer to each assay tube, and $0.2 \mathrm{ml}$ of the ureacontaining buffer to the standard tubes.

The method we employed for investigation of immunochemical identity by serial dilution has been described previously (1). The sample was dialyzed free of urea before the serial dilutions were prepared.

Studics on the effects of freczing and thawing on $B G H$. In experiments in which we studied the effects of repeated freezing and thawing on $\mathrm{BGH}$, the following technique was employed: an 8-12-ml aliquot of $\mathrm{BGH}$ in barbital buffer containing $0.3 \%$ albumin was frozen rapidly in a dry icemethanol mixture and thawed in tap water at room temperature, and this process was repeated six times in the course of about $45 \mathrm{~min}$. After this, the sample was subjected to gel filtration.

Preparation of saline or barbital pituitary extracts. Pituitary glands were obtained from nonacromegalic patients at autopsy within $12 \mathrm{~h}$ of death. Portions of the anterior lobe tissue were homogenized in $0.9 \%$ saline (J. L. and H. L.) or iced barbital buffer (M. W.), the homogenates were centrifuged at $6,000 \mathrm{rpm}$ for $30 \mathrm{~min}$, and the supernate was decanted and immediately placed on the column.

Sucrose gradicnt contrifugation. The sedimentation properties of selected forms of IRGH were studied by centrifugation in a sucrose gradient. A linear 5-20\% sucrose gradient was prepared in $4.7 \mathrm{ml}$ of $0.3 \mathrm{M} \mathrm{NaCl}$ and $0.04 \mathrm{M}$ barbital buffer, $\mathrm{pH} 8.2$, by the method described by Gerhart (7). Over the top of the gradient, we layered selected specimens of IRGH in $0.2 \mathrm{ml}$ of the NaCl-barbital solution, to which had been added $\left.{ }^{125} \mathrm{I}\right] \mathrm{pHGH}$ (mol wt 22,000 ) and $\left[{ }^{131} \mathrm{I}\right]$ albumin (mol wt 69,000 ), which served as markers. The tubes were then centrifuged at $50,000 \mathrm{rpm}$ for $17 \mathrm{~h}$ at $13^{\circ} \mathrm{C}$ in a Beckman L2-65 centrifuge with an SW-50 rotor (Beckman Instruments, Inc., Spinco Div., Palo Alto, Calif.). 30 fractions of approximately $0.16 \mathrm{ml}$ each were then collected from the bottom of each gradient tube and aliquots of these fractions were assayed for IRGH, ${ }^{131} \mathrm{I}$, and ${ }^{125} \mathrm{I}$. It was found that the amounts of sucrose and $\mathrm{NaCl}$ carried over to the assay tubes in these studies had no effect on the immunoassay.

Trypsinization studics. Trypsinization of selected fractions of IRGH were performed by adding chymotrypsinfree trypsin (Sigma Chemical Co., St. Louis, Mo.) in varying concentrations to solutions of IRGH in the albumincontaining barbital buffer, and incubating for 30-45 min at $37^{\circ} \mathrm{C}$. The trypsin was then inactivated by the addition of soy bean trypsin inhibitor (Sigma Chemical Co.) to a final concentration twice that of the trypsin.

\section{RESULTS}

Gel filtration of saline and barbital extracts of human pituitary. The gel filtration pattern of a saline extract of human pituitary (subject J. L.) is illustrated in Fig. 1A, and two discrete peaks of IRGH are apparent. The major peak, representing $79 \%$ of the total IRGH in the effluent, migrated identically with iodinated $\mathrm{pHGH}$ and thus was identical in its migration pattern to $\mathrm{LGH}$ in plasma (1). The minor peak, representing $17 \%$ of total IRGH, eluted between LGH and albumin and thus migrated like $\mathrm{BGH}$ in plasma (1). $4 \%$ of the IRGH appeared in a shoulder between the void volume and the $\mathrm{BGH}$ peak. Very similar results have been obtained on gel filtration of a saline extract of 

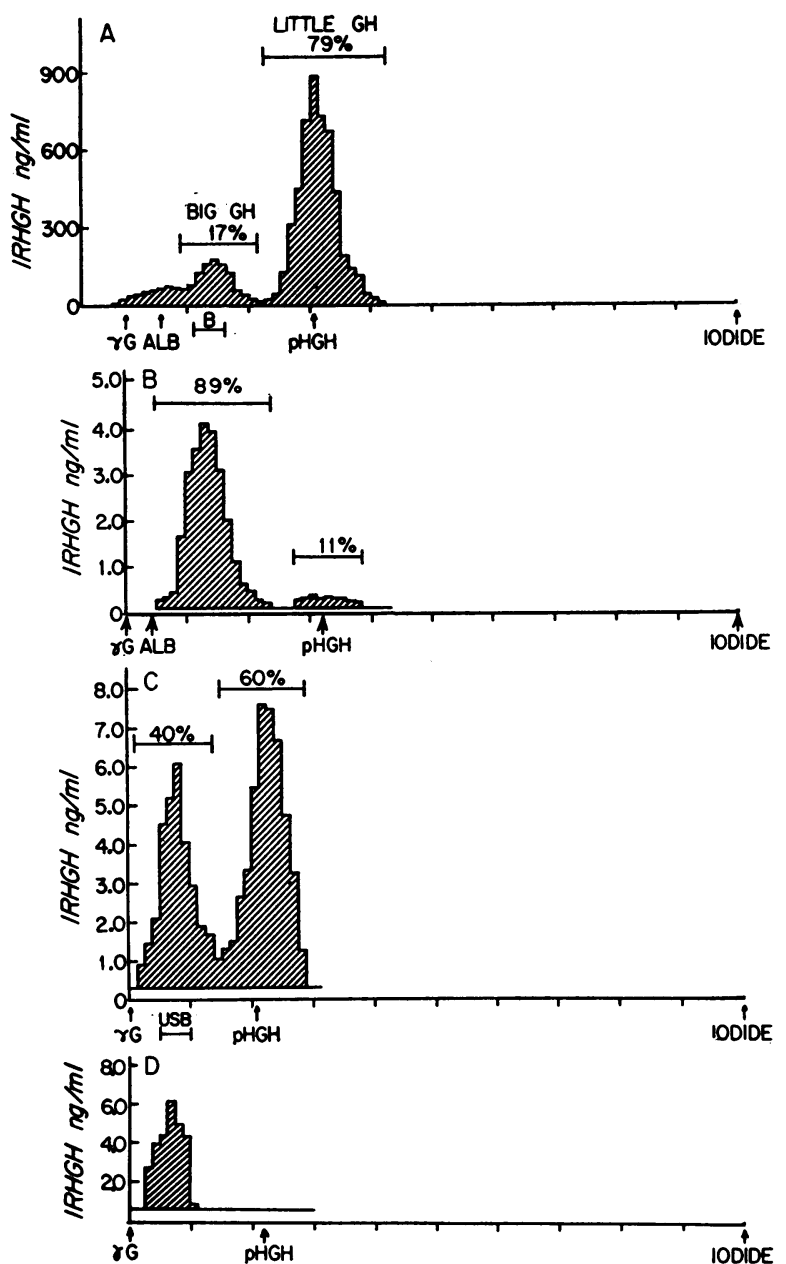

Figure 1 Gel filtration studies (Sephadex G-75) of a saline extract of human anterior pituitary from patient J. L. The arrows beneath the base line indicate the peaks of the radioiodinated column markers. The vertical lines beneath the base line indicate the percent of the effluent volume between the peaks of gamma globulin and iodide, with each line representing a tenth percentile. The base line indicates the lower limit of sensitivity of the immunoassay employed. The numbers over each peak indicate the percent of total effluent IRGH contained within the peak. (A) Gel filtration in barbital buffer of $5 \mathrm{ml}$ of a saline extract of anterior pituitary. The brackets labeled " $B$ " indicate the fractions pooled for the rechromatography studies shown in B and C. Recovery of filtered IRGH was $72 \%$. (B) Gel filtration in barbital buffer of $1 \mathrm{ml}$ of pooled $\mathrm{BGH}$ ("B" from Fig. 1A) after $70 \mathrm{~h}$ storage at $4^{\circ} \mathrm{C}$. Recovery of filtered IRGH was $74 \%$. (C) Gel filtration in $8 \mathrm{M}$ urea of $5 \mathrm{ml}$ of pooled BGH ("B" from Fig. 1A) after $70 \mathrm{~h}$ storage at $4^{\circ} \mathrm{C}$. Recovery of filtered IRGH was $69 \%$. The brackets labeled "USB" (for urea-stable $\mathrm{BGH}$ ) denote the fractions pooled for rechromatography in study (D). (D) Gel filtration in $8 \mathrm{M}$ urea of $12 \mathrm{ml}$ of pooled USB from Fig. 1C. Recovery of filtered IRGH was $114 \%$.
TABLE I

Summary of Data Concerning Big and Little IRGH in Plasma and in Pituitary Extracts

\begin{tabular}{lrccc}
\hline \multicolumn{1}{c}{ Subject* } & $\begin{array}{c}\text { Total } \\
\text { plasma } \\
\text { IRGH }\end{array}$ & $\begin{array}{c}\text { Big } \\
\text { IRGH }\end{array}$ & $\begin{array}{c}\text { Little } \\
\text { IRGH }\end{array}$ & $\begin{array}{c}\text { Pre-big } \\
\text { IRGH }\end{array}$ \\
& $n g / m l$ & & $\%$ & \\
Acromegalics & & & & \\
G. C. & 21 & 16 & 78 & 6 \\
P. F. & 27 & 28 & 68 & 4 \\
E. M. & 50 & 11 & 89 & 0 \\
M. H. & 129 & 13 & 82 & 5 \\
B. L. & 176 & 25 & 75 & 0 \\
B. S. & 88 & 28 & 70 & 2 \\
T. G. & 50 & 14 & 86 & 0 \\
A. S. & 125 & 14 & 83 & 3 \\
Normals (post-hypoglycemia) & & & & \\
K. T. & 25 & 39 & 60 & 1 \\
A. F. & 26 & 24 & 70 & 6 \\
T. M. & 24 & 28 & 72 & 0 \\
B. K. & 37 & 25 & 67 & 8 \\
Pituitary extracts & & & & \\
J. L. (saline) & & 17 & 79 & 4 \\
H. L. (saline) & & 12 & 85 & 3 \\
M. W. (barbital) & & 11 & 85 & 4 \\
N. I. H. immunochemical & & & & \\
grade HGH & & 10 & 86 & 4 \\
Clinical grade HGH & & & 84 & 4 \\
\hline
\end{tabular}

* Data concerning the last four acromegalics, the last two normal subjects, and the clinical grade HGH have been presented elsewhere (1).

$\ddagger$ This term refers to IRGH eluting between the BGH peak and the void volume.

the pituitary of a second patient (H. L.), and of a $0.04 \mathrm{M}$ barbital extract of a third patient (M. W.), as well as on filtration of immunochemical grade pituitary HGH (Table I).

When the BGH obtained from the saline extract of patient J. L. was rechromatographed, $89 \%$ ran as $\mathrm{BGH}$ (Fig. 1B).

Filtration of $B G H$ in urea. The effect of $8 \mathrm{M}$ urea on $\mathrm{BGH}$ was studied because this material is known to have the capacity to dissociate peptide subunits held together by noncovalent bonds (8). When $\mathrm{BGH}$ extracted from the pituitary of J. L. (Fig. 1A) was refiltered in $8 \mathrm{M}$ urea, $60 \%$ migrated as LGH, eluting at the same point as iodinated $\mathrm{pHGH}$, while the remainder ran as $\mathrm{BGH}$ (Fig. 1C). ${ }^{2} \mathrm{~A}$ portion of the material that ran as $\mathrm{BGH}$ in the presence of urea ("urea-stable" BGH) was then refiltered in $8 \mathrm{M}$ urea and all of it ran as BGH (Fig. 1D). Very similar results were obtained in a study of the $\mathrm{BGH}$ fraction

\footnotetext{
${ }^{2}$ In the presence of urea, the albumin, BGH, LGH, and $\left.{ }^{125} \mathrm{I}\right] \mathrm{pHGH}$ all eluted earlier than in the absence of urea, and this effect of urea has been observed for other proteins as well (9). However, the relation of these fractions remained the same, in that LGH eluted at the same point as the $\left[{ }^{125} \mathrm{I}\right] \mathrm{pHGH}$, and $\mathrm{BGH}$ appeared between $\mathrm{LGH}$ and $\left[{ }^{131} \mathrm{I}\right]$ albumin.
} 
from the saline pituitary extract of patient $\mathrm{H}$. L.; on initial filtration of the $\mathrm{BGH}$ in $8 \mathrm{M}$ urea, $41 \%$ ran as $\mathrm{BGH}$ and $59 \%$ ran as $\mathrm{LGH}$, but when the urea-stable $\mathrm{BGH}$ fraction was refiltered in $8 \mathrm{M}$ urea, over $99 \%$ of it ran as BGH. These observations indicate that there are at least two fractions of $B G H$ in human pituitary: one form that dissociates in the presence of urea to yield LGH, and a second form that is stable in the presence of urea.

Similar results were observed in studies of BGH extracted from acromegalic plasma (Fig. 2). When plasma BGH was refiltered in barbital buffer $40 \mathrm{~h}$ after it had been extracted from plasma into the buffer, $30 \%$ ran as LGH (Fig. 2B), and when the same fraction of $\mathrm{BGH}$ was filtered in $8 \mathrm{M}$ urea, $63 \%$ ran as LGH (Fig. 2C). However, when the ureastable fraction of $\mathrm{BGH}$ in Fig. 2C was refiltered in $8 \mathrm{M}$ urea, all of it maintained its identity as $\mathrm{BGH}$ (Fig. 2D). Thus, there appear to be "labile" and urea-stable fractions of $\mathrm{BGH}$ in acromegalic plasma as well as in pituitary.

In a study of $\mathrm{BGH}$ extracted from the plasma of another acromegalic subject, M. H., on filtration of the $\mathrm{BGH}$ fraction in $8 \mathrm{M}$ urea, $20 \%$ ran as $\mathrm{BGH}$, with the remainder eluting as LGH. Similarly, $18 \%$ of $\mathrm{BGH}$ extracted from the plasma of a normal subject, A. F., ran as BGH in urea, with the remainder running as $\mathrm{LGH}$. When $\mathrm{BGH}$ extracted from immunochemical grade pituitary $\mathrm{HGH}$ was filtered in $8 \mathrm{M}$ urea, $52 \%$ ran as $\mathrm{BGH}$ and $48 \%$ as $\mathrm{LGH}$.

The LGH generated from pituitary by treatment with $8 \mathrm{M}$ urea (Fig. 1C) was compared with the $\mathrm{LGH}$ present in an untreated saline extract of pituitary (Fig. 1A) with regard to its reactivity with the antibody employed in our immunoassay. In a serial dilution study, no significant difference between the bound/free $(B / F)$ curves of these two LGH preparations and the N.I.H. pituitary $\mathrm{HGH}$ standard was found (Figs. 3A and $3 \mathrm{~B}$ ).

Effects of repeated freezing and thawing of $B G H$. Under appropriate conditions, freezing and thawing, like exposure to $8 \mathrm{M}$ urea, appears to cause dissociation of peptide units linked by noncovalent bonds (10). To investigate further the possibility that there are two discrete forms of $\mathrm{BGH}$, an aliquot of the $\mathrm{BGH}$ that had been extracted from the pituitary of J. L. (Fig. 1A) was subjected to repeated freezing and thawing and then refiltered in barbital buffer, and it was found that $57 \%$ of the IRGH migrated as LGH with $43 \%$ eluting as $\mathrm{BGH}$ (Fig. $4 \mathrm{~A}$ ). The fraction of $\mathrm{BGH}$ that proved to be freeze-stable was again subjected to freeze-thaw treatment and refiltered in barbital, and $82 \%$ of it maintained its identity as BGH (Fig. 4B). Similar studies were performed with BGH from acro-

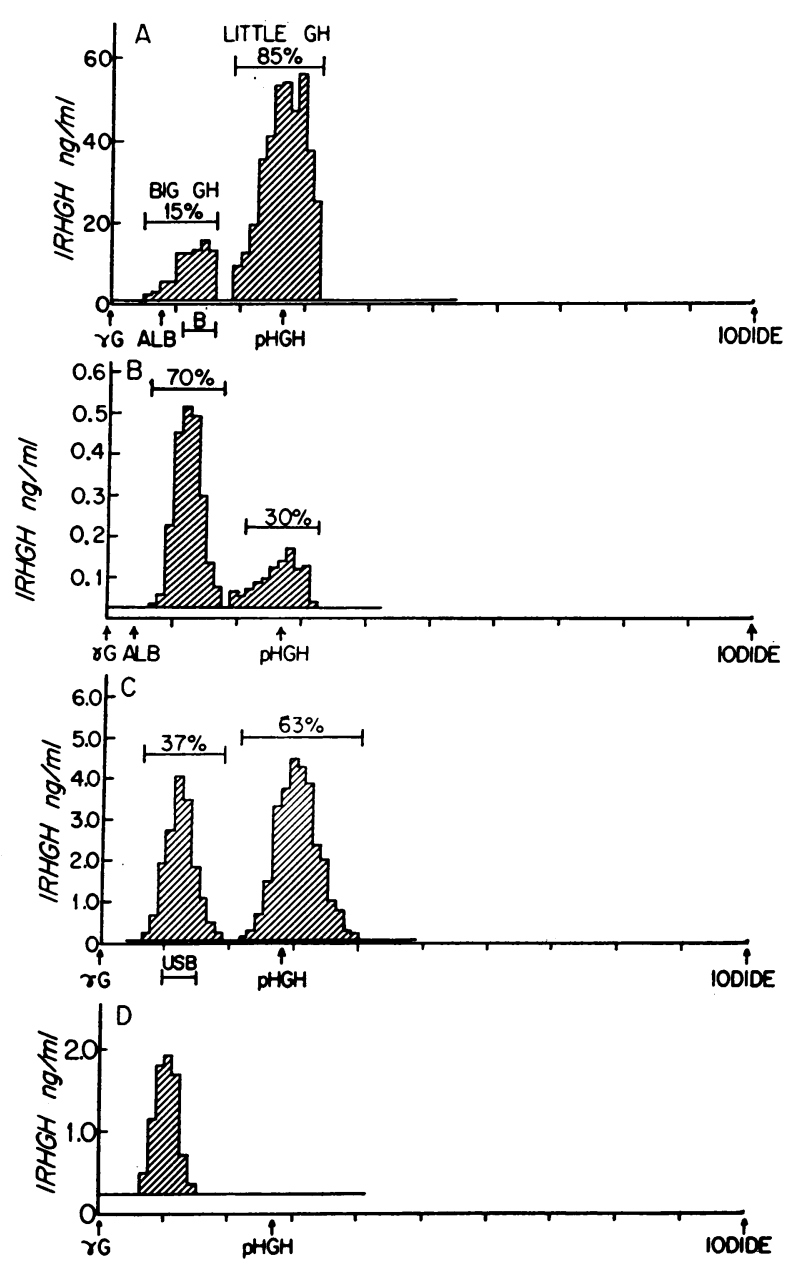

Figure 2 Gel filtration studies (Sephadex G-75) of plasma from acromegalic patient B. L. (A) Gel filtration in barbital buffer of $10 \mathrm{ml}$ of frozen plasma from an acromegalic patient. Recovery of filtered IRGH was $100 \%$. (B) Gel filtration in barbital buffer of $1 \mathrm{ml}$ of the fraction of $\mathrm{BGH}$ labeled "B" in Fig. 2A, after $40 \mathrm{~h}$ storage at $4^{\circ} \mathrm{C}$. Recovery of filtered IRGH was $102 \%$. (C) Gel filtration in $8 \mathrm{M}$ urea of $12 \mathrm{ml}$ of fraction "B" from Fig. 2A. Recovery of filtered IRGH was $116 \%$. (D) Gel filtration in $8 \mathrm{M}$ urea of $12 \mathrm{ml}$ of urea-stable BGH (USB) from Fig. 2C. Recovery of filtered IRGH was $90 \%$.

megalic plasma (Fig. 5). When BGH from plasma was refiltered in barbital after $40 \mathrm{~h}$ of storage in barbital at $4^{\circ} \mathrm{C}, 48 \%$ ran as $\mathrm{LGH}$ (Fig. 5B), and when an aliquot of the same $\mathrm{BGH}$ was refiltered after repeated freezing and thawing, $71 \%$ ran as LGH (Fig. $5 \mathrm{C})$. However, when the freeze-stable fraction of $\mathrm{BGH}$ was again subjected to repeated freezing and thawing, and refiltered in barbital, all of it ran as $\mathrm{BGH}$ (Fig. 5D). These observations indicate that the pituitary and plasma BGH examined in this study consist of two forms, one of which dissociates during storage and 


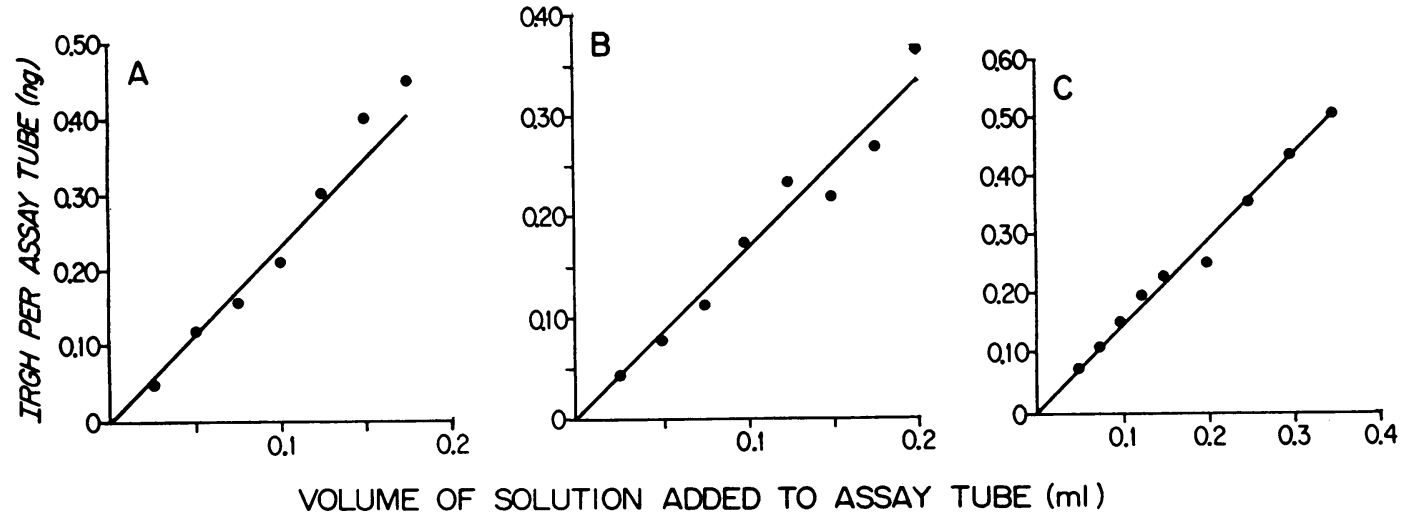

FIGURE 3 Serial dilution studies of the immunoreactivity of three forms of LGH prepared from a saline extract of human pituitary, in an assay system in which N.I.H. immunochemical grade pituitary $\mathrm{HGH}$ was employed as the standard. In each study, if the $\mathrm{B} / \mathrm{F}$ curve of the material being assayed was identical with that of the HGH standard, all of the points would fall along the straight line. (A) Study of LGH extracted from untreated saline extract of pituitary. (B) Study of LGH generated by exposure of pituitary BGH to $8 \mathrm{M}$ urea. (C) Study of LGH generated by treatment of urea-stable BGH with trypsin.

during freezing and thawing with consequent liberation of $\mathrm{LGH}$, and one of which is not dissociated under these conditions.

Relation of urea-stable $B G H$ to freeze-stable $B G H$. Since both $8 \mathrm{M}$ urea and freeze-thaw treatment appear to reveal the presence of a labile and a stable form of $\mathrm{BGH}$, studies were performed to determine if the ureastable fraction of $\mathrm{BGH}$ is identical to the freeze-stable fraction. To investigate this possibility, a sample of

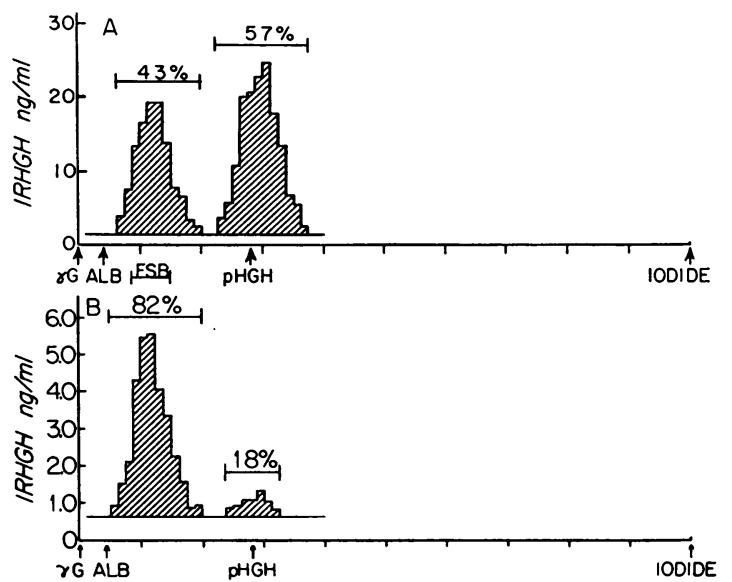

FIgUre 4 Gel filtration studies (Sephadex G-75) of the effect of freezing and thawing on pituitary BGH. (A) Gel filtration in barbital buffer of $11 \mathrm{ml}$ of the fraction of pituitary BGH designated "B" in Fig. 1A, after repeated freezing and thawing. Recovery of filtered IRGH was $117 \%$. (B) Gel filtration in barbital buffer of $10 \mathrm{ml}$ of the fraction designated "FSB (freeze-stable BGH)" in Fig. 4A, after repeated freezing and thawing. Recovery of filtered IRGH was $73 \%$. urea-stable $\mathrm{BGH}$ was dialyzed free of urea, subjected to repeated freezing and thawing, and refiltered in barbital buffer (Fig. 6A). It was found that all of the material eluted as $\mathrm{BGH}$, indicating that the ureastable $\mathrm{BGH}$ was entirely freeze-stable. Similarly, an aliquot of freeze-stable $\mathrm{BGH}$ was subjected to gel filtration in $8 \mathrm{M}$ urea and most of this $(86 \%)$ ran as $\mathrm{BGH}$, indicating that most of the freeze-stable $\mathrm{BGH}$ was urea-stable (Fig. 6B). These results suggest that most, if not all, of the freeze-stable $\mathrm{BGH}$ appears to be identical with the urea-stable fraction.

The urea-stable and freeze-stable form of BGH does not appear to dissociate on standing in barbital buffer, for on many occasions we have rechromatographed samples of this form of $\mathrm{BGH}$ after they had stood in barbital buffer at $4^{\circ} \mathrm{C}$ for several days, and noted less than $5 \%$ conversion to $\mathrm{LGH}$ (Figs. 1D, 2D, 5D, 6A, and $8 \mathrm{~B})$. Thus the fraction of $\mathrm{BGH}$ that tends to dissociate on prolonged standing in barbital buffer (Figs. $2 \mathrm{~B}$ and $5 \mathrm{~B}$ ) presumably represents a portion of the fraction of $\mathrm{BGH}$ subject to dissociation by $8 \mathrm{M}$ urea and freezing.

Sucrose density centrifugation of urea-stable $B G H$. To assess the molecular weight of pituitary urea-stable $\mathrm{BGH}$ by a technique other than gel filtration, an aliquot of this material was subjected to centrifugation in a 5-20\% sucrose density gradient. As seen in Fig. $7 \mathrm{~A}$, after centrifugation at $50,000 \mathrm{rpm}$ for $17 \mathrm{~h}$, ureastable BGH appeared as a discrete peak between [ $\left.{ }^{225} \mathrm{I}\right]$ albumin and $\left[{ }^{125} \mathrm{I}\right] \mathrm{pHGH}$, at a position indicative of a mol wt of approximately 40,500 (11). This corresponds closely to the molecular weight of $\mathrm{BGH}$ as estimated by gel filtration (1). When an aliquot of 
pituitary LGH was centrifuged, it migrated identically with $\left[{ }^{125} \mathrm{I}\right] \mathrm{pHGH}$ (Fig. 7B).

Effect of trypsinization of urea-stable BGH. To investigate the possibility that urea-stable $\mathrm{BGH}$ might consist of LGH bound to another moiety by a peptide
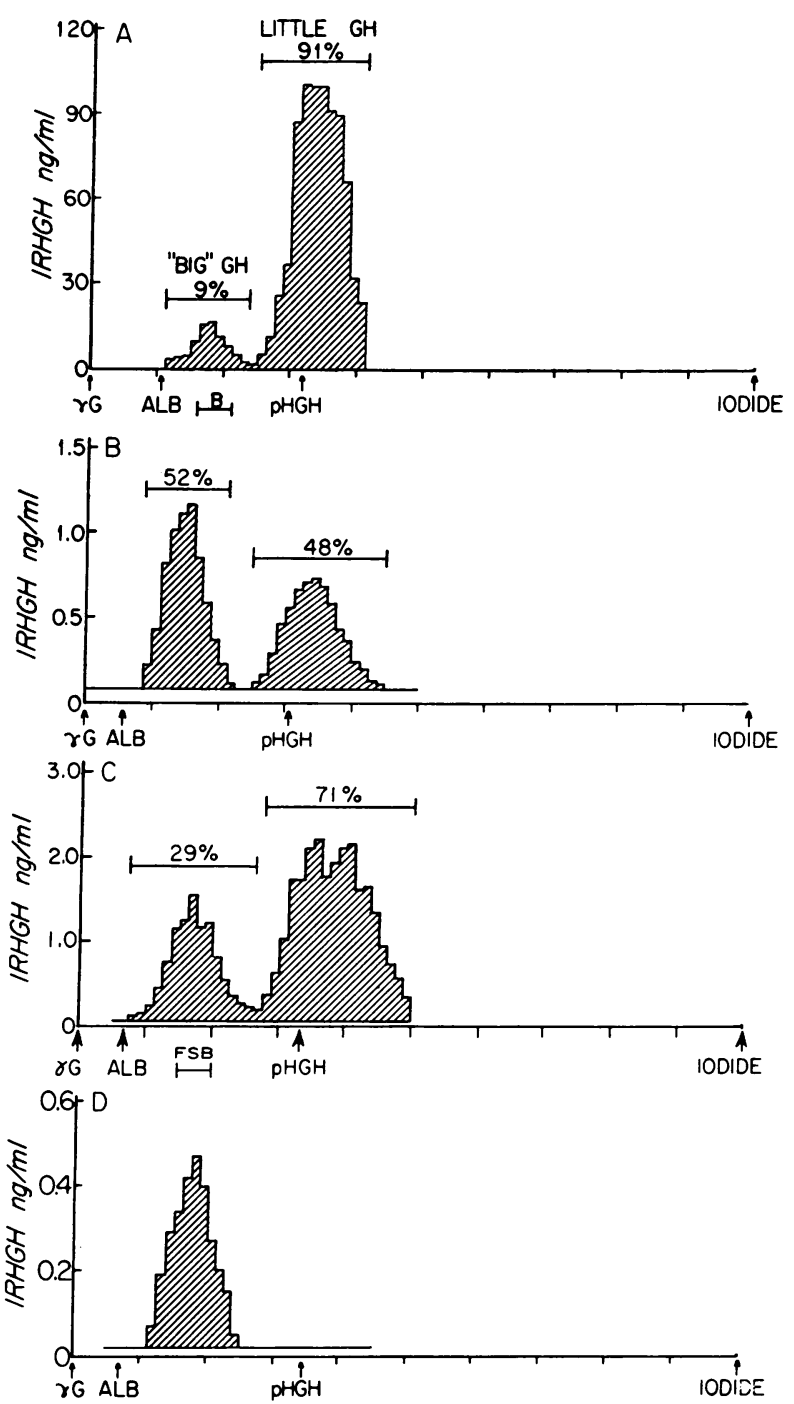

Figure 5 Gel filtration studies (Sephadex G-75) on the effect of freezing and thawing on BGH from plasma. (A) Gel filtration in barbital buffer of $10 \mathrm{ml}$ of acromegalic plasma from patient B. L. Recovery of filtered IRGH was $169 \%$. (B) Gel filtration in barbital buffer of $2.5 \mathrm{ml}$ of the fraction of $\mathrm{BGH}$ designated " $\mathrm{B}$ " in Fig. $5 \mathrm{~A}$, after $40 \mathrm{~h}$ storage at $4^{\circ} \mathrm{C}$. Recovery of filtered IRGH was $140 \%$. (C) Gel filtration in barbital buffer of $12 \mathrm{ml}$ of the fraction of BGH designated " $\mathrm{B}$ " in Fig. 5A, after repeated freezing and thawing. Recovery of filtered IRGH was $91 \%$. (D) Gel filtration in barbital buffer of $12 \mathrm{ml}$ of the fraction designated freeze-stable BGH (FSB) in Fig. 5C, after repeated freezing and thawing. Recovery of filtered IRGH was $68 \%$.

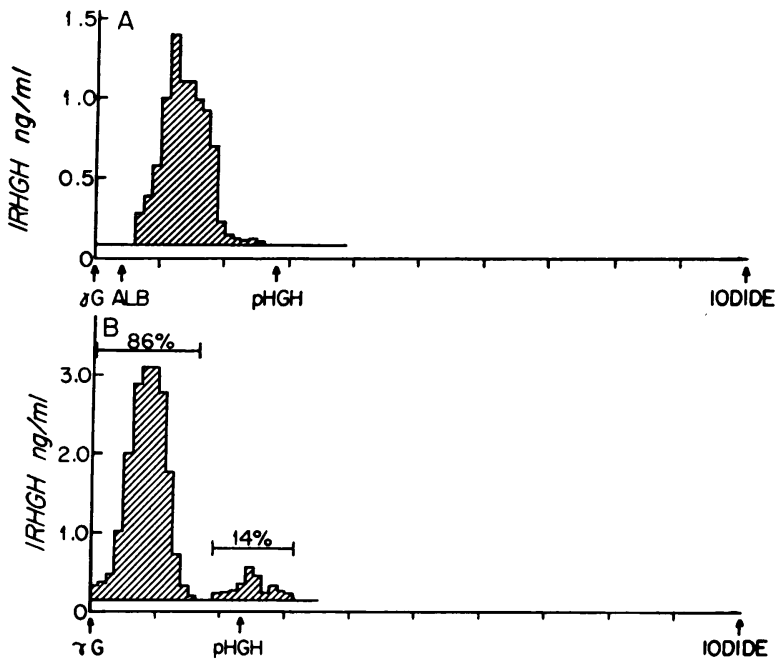

FIGURE 6 Study of the relation between urea-stable $B G H$ and freeze-stable BGH. (A) Gel filtration in barbital buffer of $12 \mathrm{ml}$ of urea-stable $\mathrm{BGH}$, dialyzed free of urea, and subjected to repeated freezing and thawing. Recovery of filtered IRGH was $64 \%$. (B) Gel filtration in $8 \mathrm{M}$ urea of $12 \mathrm{ml}$ of freeze-stable BGH. Recovery of filtered IRGH was $95 \%$.

bond, we studied the effects of trypsin on this fraction. In this study we decided to employ a concentration of trypsin that would not cause significant destruction of LGH itself. To determine the appropriate concentration, in preliminary studies an aliquot of pituitary LGH was exposed to varying concentrations of trypsin for $30 \mathrm{~min}$ at $37^{\circ} \mathrm{C}$, the reaction stopped by the addition of soy bean trypsin inhibitor, and the IRGH concentration measured and compared with that of an untrypsinized aliquot. It was found that there was a $64 \%$ decrease in IRGH after incubation with $200 \mu \mathrm{g} / \mathrm{ml}$ trypsin, a $35 \%$ decrease with $100 \mu \mathrm{g} / \mathrm{ml}$, and an $18 \%$ decrease with $20 \mu \mathrm{g} / \mathrm{ml}$, but there was no diminution in IRGH after incubation with $2 \mu \mathrm{g} / \mathrm{ml}$. Incubation of pituitary urea-stable $\mathrm{BGH}$ for $30 \mathrm{~min}$ with $2 \mu \mathrm{g} / \mathrm{ml}$ of trypsin also caused no decrease in total IRGH concentration. Subsequently, we performed our studies on the conversion of urea-stable BGH to LGH with either 1.0 or $1.5 \mu \mathrm{g} / \mathrm{ml}$ trypsin.

An aliquot of urea-stable $\mathrm{BGH}$ was prepared from a saline extract of human pituitary (subject $H$. L.) by the methods described previously, and the material was dialyzed against barbital buffer to free it of urea. Trypsin was added to one portion in a concentration of $1 \mu \mathrm{g} / \mathrm{ml}$ and it was incubated for $30 \mathrm{~min}$ at $37^{\circ} \mathrm{C}$, after which $2 \mu \mathrm{g} / \mathrm{ml}$ soy bean trypsin inhibitor was added. To a second portion, we added the trypsin inhibitor and trypsin simultaneously, before the $30-\mathrm{min}$ incubation, and hence this portion was not exposed to effective trypsinization. Both aliquots were then gel- 

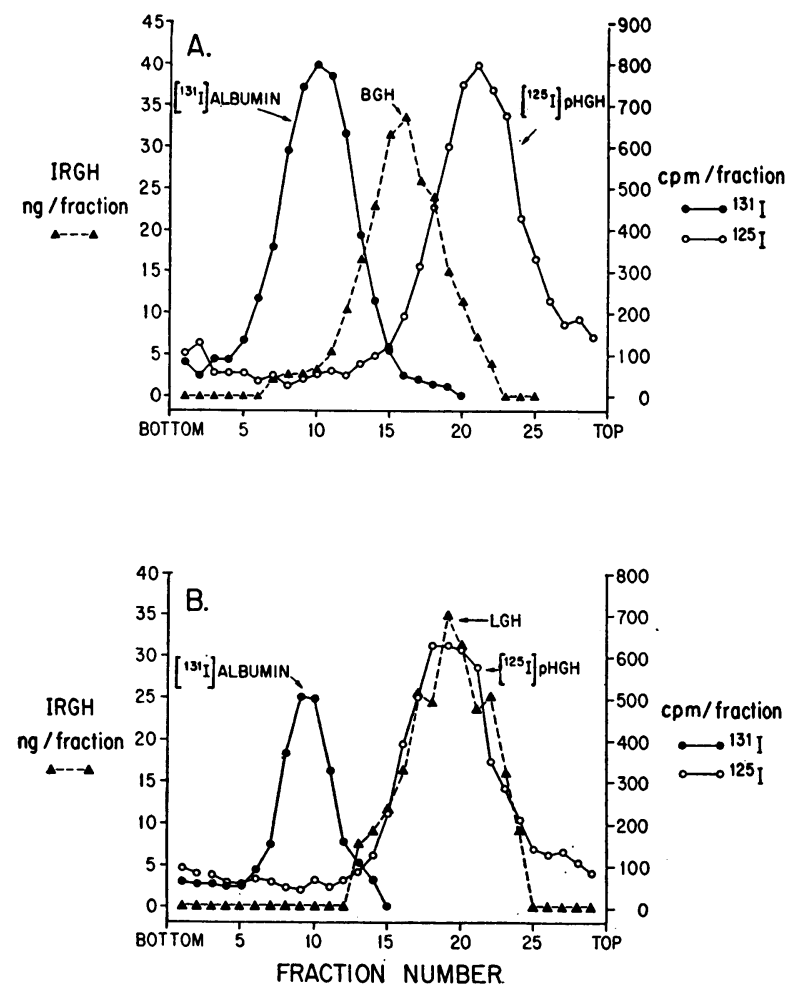

FIGURE 7 Sucrose gradient centrifugation of urea-stable BGH and of LGH. (A) Centrifugation of pituitary ureastable BGH, [ $\left.{ }^{131} \mathrm{I}\right]$ albumin and $\left[{ }^{125} \mathrm{I}\right] \mathrm{pHGH}$ in a $5-20 \%$ sucrose gradient. Fractions in which the IRGH content is indicated as zero contained less than 2 ng. (B) Centrifugation of pituitary LGH, [ $\left.{ }^{131} \mathrm{I}\right]$ albumin and $\left[{ }^{125} \mathrm{I}\right] \mathrm{pHGH}$ in a 5-20\% sucrose gradient. Fractions in which the IRGH content is indicated as zero contained less than $7 \mathrm{ng}$.

filtered in barbital buffer. In the sample of trypsinized $\mathrm{BGH}, 36 \%$ ran as $\mathrm{LGH}$, indicating that trypsin had converted some of the BGH to LGH (Fig. 8A), whereas in the untrypsinized sample, almost all of the BGH retained its identity (Fig. 8B). Similarly, trypsinization of urea-stable $\mathrm{BGH}$ from a saline extract of the pituitary of another subject (J. L.) converted $48 \%$ of the $\mathrm{BGH}$ to $\mathrm{LGH}$; trypsinization of ureastable $\mathrm{BGH}$ from immunochemical grade $\mathrm{HGH}$ converted $44 \%$ to $\mathrm{LGH}$; and trypsinization of urea-stable $\mathrm{BGH}$ from the plasma of an acromegalic patient (B. L.) converted $59 \%$ to LGH.

Since a large fraction of urea-stable $\mathrm{BGH}$ was not converted to LGH by trypsinization (Fig. 8A), the possibility was considered that urea-stable BGH may consist of two separate components, which differ in their response to trypsin. To investigate this possibility, an aliquot of the $\mathrm{BGH}$ that retained its identity after trypsinization ("TSB" in Fig. 8A) was again exposed to trypsin and only $13 \%$ was converted to LGH (Fig. $8 \mathrm{C})$. For comparison, in a simultaneous experiment an aliquot of BGH, not exposed to effective trypsinization previously, was treated with trypsin under identical conditions, and $42 \%$ was converted to LGH (Fig. $8 \mathrm{D})$. In two other experiments in which initial treatment with trypsin converted $48-52 \%$ of urea-stable pituitary $\mathrm{BGH}$ to $\mathrm{LGH}$, on re-exposure of the trypsinstable $\mathrm{BGH}$ to trypsin, there was only $14-24 \%$ conversion to $\mathrm{LGH}$.

To further study this problem, we performed an additional study, depicted in Fig. 9. An aliquot of ureastable $\mathrm{BGH}$ was trypsinized with conversion of $51 \%$ to LGH (Fig. 9A). An aliquot of the BGH that maintained its identity despite trypsinization ("TSB" in Fig. 9A) was then retrypsinized and only $16 \%$ was converted to LGH (Fig. 9B). The BGH that maintained its identity after this second trypsinization ("TSB" in Fig. 9B) was again exposed to trypsin and essentially the same proportion, $17 \%$, was converted to $\mathrm{LGH}$ (Fig. 9C). These observations suggest that urea-stable BGH may consist of at least two components, one readily convertible by trypsin to $\mathrm{LGH}$, and a second less readily convertible.

We next attempted to determine if trypsinization converted some of the urea-stable $\mathrm{BGH}$ to a urea-labile form. A portion of urea-stable BGH was trypsinized and on gel filtration, $40 \%$ ran as LGH. The portion that maintained its identity as $\mathrm{BGH}$ after trypsinization was then run on the column in $8 \mathrm{M}$ urea and only $4 \%$ of it eluted as LGH. Thus trypsin does not appear to transform urea-stable $\mathrm{BGH}$ to a form of $\mathrm{BGH}$ that dissociates in urea.

LGH generated by trypsinization of urea-stable BGH from pituitary was compared with LGH found in an untreated saline extract of pituitary, and in a dilution study it was found to have a similar $\mathrm{B} / \mathrm{F}$ curve (Fig. 3C).

\section{DISCUSSION}

As illustrated in Table $I$, we have found a major component of $\mathrm{LGH}$ and minor component of $\mathrm{BGH}$ in every sample of human plasma and pituitary we have studied. These include plasma samples from eight acromegalic and four normal subjects, one barbital and two saline extracts of pituitary, and clinical grade and immunochemical grade preparations of pituitary $\mathrm{GH}$.

In the present study, it was observed that over half of the BGH complex found in the pituitary and plasma migrated as LGH after exposure to $8 \mathrm{M}$ urea (Figs. $1 \mathrm{C}$ and $2 \mathrm{C}$ ) or after repeated freezing and thawing (Figs. 4A and $5 \mathrm{C}$ ). The fraction of $\mathrm{BGH}$ not susceptible to dissociation by urea appears to be very similar to or identical with the fraction not converted to LGH by freezing, for all of a sample of urea-stable BGH was found to be freeze-stable, and most of an aliquot of 


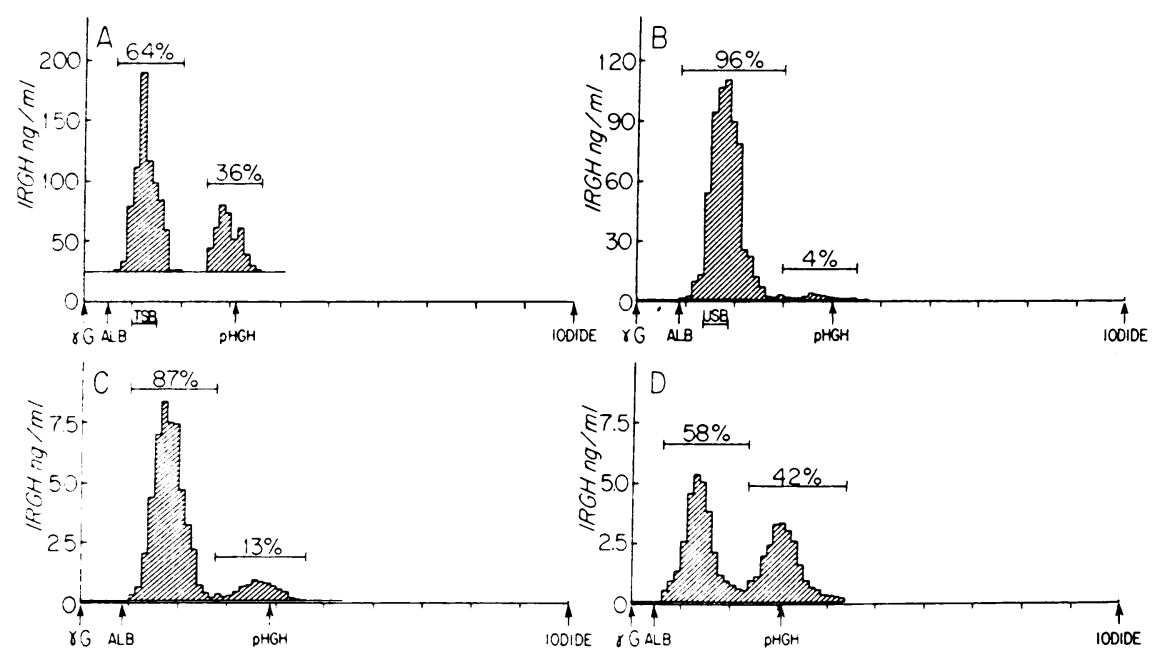

FIGURE 8 Study of the effect of trypsin on urea-stable $B G H$ previously prepared from a saline extract of pituitary. (A) Gel filtration in barbital buffer of $6 \mathrm{ml}$ of urea-stable BGH, immediately after a 30-min incubation with trypsin $(1 \mu \mathrm{g} / \mathrm{ml})$ and subsequent addition of trypsin inhibitor $(2 \mu \mathrm{g} / \mathrm{ml})$. Recovery of filtered IRGH was $112 \%$. (B) Gel filtration in barbital buffer of $3 \mathrm{ml}$ of urea-stable BGH immediately after a 30-min incubation with inactivated trypsin. (Trypsin inhibitor, $2 \mu \mathrm{g} / \mathrm{ml}$, was added to the sample along with trypsin $1 \mu \mathrm{g} / \mathrm{ml}$, before the incubation.) Recovery of filtered IRGH was $102 \%$. (C) Gel filtration in barbital buffer of $2 \mathrm{ml}$ of trypsin-stable BGH (TSB) from Fig. 8A, immediately after the same treatment employed in study A. The recovery of filtered IRGH was $100 \%$. (D) Gel filtration in barbital buffer of $4 \mathrm{ml}$ of the fraction designated urea-stable BGH (USB) in Fig. 8B, immediately after the same treatment as that employed in study A. Recovery of filtered IRGH was $102 \%$.

freeze-stable $\mathrm{BGH}$ was found to be stable in urea (Fig. 6). Since urea and freezing can dissociate subunits linked by noncovalent bonds $(8,10)$, but are not known to disrupt covalent bonds, it is likely that the fraction of $\mathrm{BGH}$ that is convertible to $\mathrm{LGH}$ by urea or freezing consists of LGH bound to another subunit by noncovalent bonds, and that the stable fraction of $\mathrm{BGH}$ consists of LGH bound to another moiety by a covalent bond or by relatively strong noncovalent bonds.

Both forms of the BGH complex elute from Sephadex at a point consistent with a molecular size about twice that of LGH. However, factors other than size can affect the migration of proteins on gel filtration (11), and therefore we turned to centrifugation as an alternative means of molecular sizing. In the study illustrated in Fig. 7A, we centrifuged urea-stable BGH in a sucrose gradient and found its sedimentation rate to be consistent with a mol wt of 40,500 , almost twice that of LGH, consistent with the results obtained on Sephadex chromatography.

It is possible that the form of $\mathrm{BGH}$ dissociated by urea and by freezing may consist at least in part of the dimer form of $\mathrm{LGH}$, for it is known that LGH dimerizes to some extent when allowed to stand in concentrations over $5 \mathrm{mg} / \mathrm{ml}$ (12), and the intracellular concentration of $\mathrm{GH}$ in the human pituitary probably exceeds this level (13). Since the dimer form of LGH dissociates slowly when allowed to stand in low concentration (12), this cound account for the tendency of extracted $\mathrm{BGH}$ to undergo partial conversion to $\mathrm{LGH}$ on prolonged standing in barbital buffer. It is also possible that some of the urea-labile form of $\mathrm{BGH}$ may consist of $\mathrm{LGH}$ bound by noncovalent bonds to some other peptide, in which case this form of $\mathrm{BGH}$ would then be analogous to thyroid-stimulating hormone, luteinizing hormone, and chorionic gonadotropin (14).

To investigate the nature of the urea-stable $\mathrm{BGH}$ extracted from pituitary, we exposed a portion of this fraction to trypsin and it was observed that mild trypsinization converted $36-52 \%$ of it to LGH. Similarly, $59 \%$ of urea-stable BGH from a sample of acromegalic plasma was converted to LGH by trypsin. The LGH generated by trypsinization of pituitary $\mathrm{BGH}$ probably is very similar to or identical with the LGH present in untreated pituitary extracts, for in addition to having the same filtration characteristics, both forms have the same $B / F$ curves (Fig. 3). Since trypsin specifically cleaves peptide bonds involving a lysine or arginine carboxyl group (15), our results suggest that much of urea-stable BGH may consist of LGH linked at its amino terminus to lysine or arginine in a second 

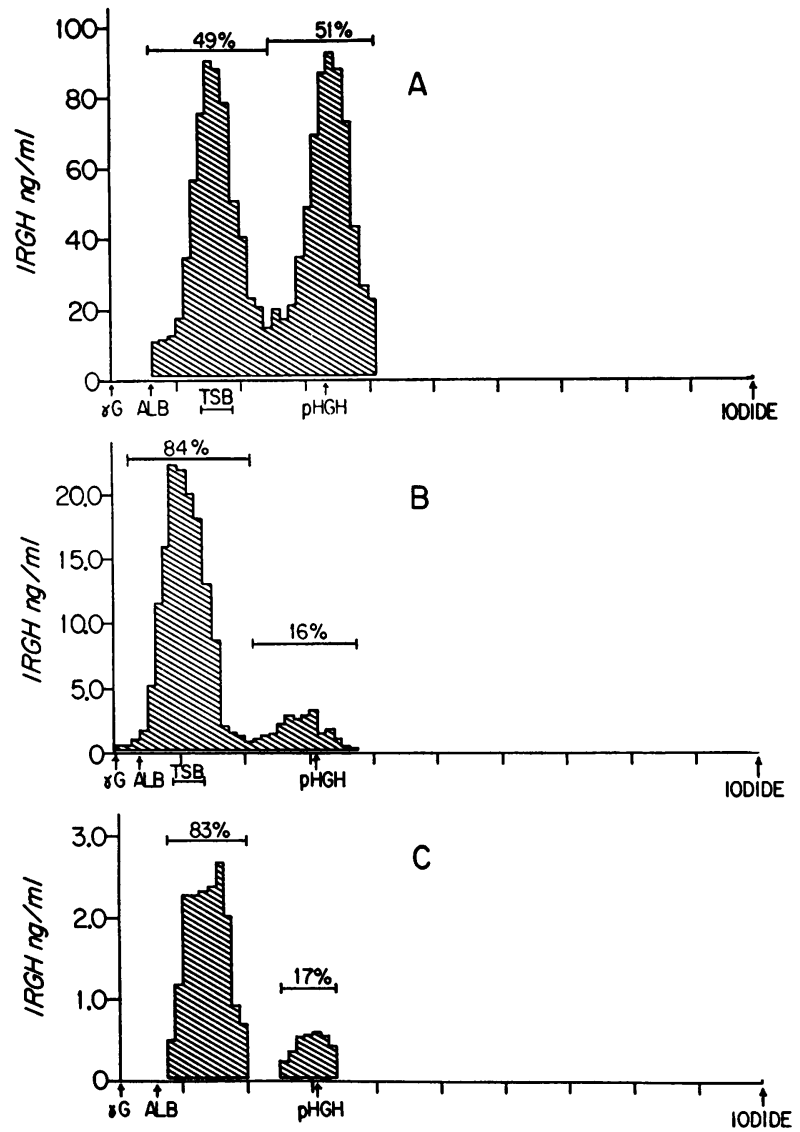

FIgURE 9 Study of the effects of repeated trypsinization on urea-stable BGH from pituitary. (A) Gel filtration in barbital buffer of $4 \mathrm{ml}$ of urea-stable BGH immediately after a 45-min incubation with trypsin $(1.5 \mu \mathrm{g} / \mathrm{ml})$. Recovery of filtered IRGH was $80 \%$. The same preparation of ureastable BGH was used as in the study depicted in Fig. 8. (B) Gel filtration in barbital buffer of $10 \mathrm{ml}$ of trypsinstable BGH (TSB) from A immediately after the same treatment employed in A. Recovery of filtered IRGH was $116 \%$. (C) Gel filtration in barbital buffer of $10 \mathrm{ml}$ of fraction TSB from Fig. 8B, immediately after the same treatment as in A. Recovery of filtered IRGH was $93 \%$.

peptide. The portion of urea-stable $\mathrm{BGH}$ that can be cleaved to LGH by trypsin is analogous to proinsulin (16), big gastrin (17), and big ACTH (18), and it is possible that this form of $\mathrm{BGH}$ is a precursor or prohormone of LGH in the pituitary, which is converted to LGH through the action of a trypsinlike enzyme. Alternatively, it is possible that the $\mathrm{BGH}$ dissociated by trypsin consists of a tightly bonded LGH dimer, and that trypsin renders it unstable by cleaving off a small portion of the monomeric components, thereby causing dissociation of the dimer. BGH itself may be derived from a larger hormone precursor, such as the very large IRGH demonstrated by Frohman, Burek, and Stachura in human pituitary, which appears to have a molecular weight of over $200,000(19,20)$.

In repeated experiments, trypsin converted $36-52 \%$ of urea-stable pituitary $\mathrm{BGH}$ to $\mathrm{LGH}$, but when the $\mathrm{BGH}$ not converted by initial trypsinization was retrypsinized under the same conditions, only 13-24\% was converted to LGH. In one experiment, a portion of $\mathrm{BGH}$ that had been exposed to trypsin twice was exposed a third time, and again $17 \%$ was converted to LGH (Fig. 8). These observations suggest that there may be two forms of urea-stable BGH, one of which is less readily dissociated by trypsin than the other.

In the present study, we have directed our attention to the fraction of IRGH eluting from Sephadex between albumin and LGH, which we have designated BGH. However, there is also a fraction of IRGH in plasma and in pituitary extracts that elutes with or before albumin, noted by us as well as by Berson and Yalow (3), Bala, Ferguson, and Beck (2), and Gorden, Hendricks, and Roth (4). In our study this material, which generally appears as a broad "shoulder" rather than a peak, has comprised on the average only $3 \%$ of total IRGH in plasma and $4 \%$ in the pituitary extracts. It may represent aggregates of LGH or $\mathrm{BGH}$, or consist of LGH bound to some other moiety. Some of it may be identical with the very large IRGH identified by Frohman, Burek, and Stachura $(19,20)$.

We do not currently know the biological and clinical significance of the existence of multiple forms of $\mathrm{BGH}$. Gorden et al. have recently found that the $\mathrm{BGH}$ complex of human pituitary and plasma is much less effective than $\mathrm{LGH}$ in displacing ${ }^{125}$ I-labeled pituitary $\mathrm{LGH}$ from the GH receptors of cultured human lymphocytes (5). In unpublished work, we have performed receptor assay studies on preparations of $\mathrm{BGH}$ complex containing $40-51 \%$ urea-stable $\mathrm{BGH}$, derived from saline extracts of two pituitaries and from immunochemical grade $\mathrm{HGH}(\mathrm{NIH}){ }^{8}$ These three $\mathrm{BGH}$ complex preparations were found to be $31-40 \%$ as effective as LGH in displacing [ $\left.{ }^{125} \mathrm{I}\right] \mathrm{LGH}$ from cell membrane receptors of pregnant rabbit liver, by the method of Tsushima and Friesen (21). In contrast, the ureastable BGH derived from these BGH complex preparations was $62-65 \%$ as effective as LGH. Similarly, in receptor assay studies employing cell membranes from pregnant rabbit mammary gland (22) and from rat liver (21), the $\mathrm{BGH}$ complex preparations were only $20-30 \%$ as effective as LGH in displacing the $\left[{ }^{125} \mathrm{I}\right]$ $\mathrm{LGH}$, whereas the urea-stable $\mathrm{BGH}$ fractions were $55-67 \%$ as effective as LGH. These data are consistent with the idea that there are at least two forms

${ }^{8}$ V. Soman and A. D. Goodman. Unpublished observations. 
of $\mathrm{BGH}$, and raise the possibility that they may differ in biologic activity.

\section{ACKNOWLEDGMENTS}

The assistance and suggestions of Dr. Vijay Soman and Mrs. Patricia Marsh are gratefully acknowledged.

This work was supported in part by a grant from the National Institutes of Health (TO1-AM-5652).

\section{REFERENCES}

1. Goodman, A. D., R. Tanenbaum, and D. Rabinowitz. 1972. Existence of two forms of immunoreactive growth hormone in human plasma. J. Clin. Endocrinol. Metab. $35: 868-878$.

2. Bala, R. M., K. A. Ferguson, and J. C. Beck. 1970. Plasma biological and immunoreactive human growth hormone-like activity. Endocrinology. 87: 506-516.

3. Berson, S. A., and R. S. Yalow. 1971. Heterogeneity of peptide hormones in plasma as revealed by radioimmunoassay. Proceedings of the XI Reunion of FrenchSpeaking Endocrinologists, Masson et Cie., Paris, 239269.

4. Gorden, P., C. M. Hendricks, and J. Roth. 1973. Evidence for "big" and "little" components of human plasma and pituitary growth hormone. J. Clin. Endocrinol. Metab. 36: 178-184.

5. Gorden, P., M. A. Lesniak, C. M. Hendricks, and J. Roth. 1973. "Big" growth hormone components from human plasma: decreased reactivity demonstrated by radioreceptor assay. Science (Wash. D. C.). 182: 829831.

6. Hunter, W. M., and F. C. Greenwood. 1962. Preparation of iodine-131 labeled human growth hormone of high specific activity. Nature. (Lond.). 194: 495-496.

7. Gerhart, J. C. 1967. Separation of subunits of proteins by zone centrifugation in a density gradient. Methods Enzymol. 11: 187-194.

8. Kauzmann, W. 1959. Some factors in the interpretation of protein denaturation. Adv. Protein Chem. 14: 1-63.

9. Olesen, H., and P. O. Pedersen. 1968. Gel filtration of albumin on Sephadex G-200 in urea. Acta Chem. Scand. 22: 1386-1394.
10. Chilson, O. E., L. A. Costello, and N. O. Kaplan. 1965. Studies on the mechanism of hybridization of lactic dehydrogenases in vitro. Biochemistry. 4: 271-281.

11. Martin, R. G., and B. N. Ames. 1961. A method for determining the sedimentation behavior of enzymes: application to protein mixtures. J. Biol. Chcm. 236: $1372-1379$.

12. Squire, P. G., and K. D. Pedersen. 1961. The sedimentation behavior of human pituitary growth hormone. $J$. Am. Chom. Soc. 83: 476-481.

13. Li, C. H., W. K. Liu, and J. S. Dixon. 1962. Human pituitary growth hormone. VI. Modified procedure of isolation and $\mathrm{NH}_{2}$-terminal amino acid sequence. Arch. Biochem. Biophys. Suppl. 1: 327-332.

14. Pierce, J. G. 1971. The subunits of pituitary thyrotropin - their relationships to other glycoprotein hormones. Endocrinology. 89: 1331-1344.

15. Bergmann, M., and J. Fruton. 1941. The specificity of proteinases. Adv. Enzymol. Relat. Areas Mol. Biol. 1: 63-98.

16. Steiner, D. F., and P. E. Oyer. 1967. The biosynthesis of insulin and a probable precursor of insulin by a human islet cell adenoma. Proc. Natl. Acad. Sci. U. S. A. 57: 473-480.

17. Yalow, R. S., and S. A. Berson. 1971. Further studies on the nature of immunoreactive gastrin in human plasma. Gastroenterology. 60: 203-214.

18. Yalow, R. S., and S. A. Berson. 1973. Characteristics of "big ACTH" in human plasma and pituitary extracts. J. Clin. Endocrinol. Metab. 36: 415-423.

19. Frohman, L. A., L. Burek, and M. E. Stachura. 1972. Characterization of growth hormone of different molecular weights in rat, dog, and human pituitaries. Endocrinology. 91 : 262-269.

20. Frohman, L. A., and M. E. Stachura. 1973. Evidence for possible precursors in the synthesis of growth hormones by rat and human fetal anterior pituitary in vitro. Mt. Sinai J. Med. 40: 414-421.

21. Tsushima, T., and H. G. Friesen. 1973. Radioreceptor assay for growth hormone. J. Clin. Endocrinol. Metab. 37: 334-337.

22. Shiu, R. P. C., P. A. Kelly, and H. G. Friesen. 1973. Radioreceptor assay for prolactin and other lactogenic hormones. Scicnce (Wash. D. C.). 180: 968-971. 